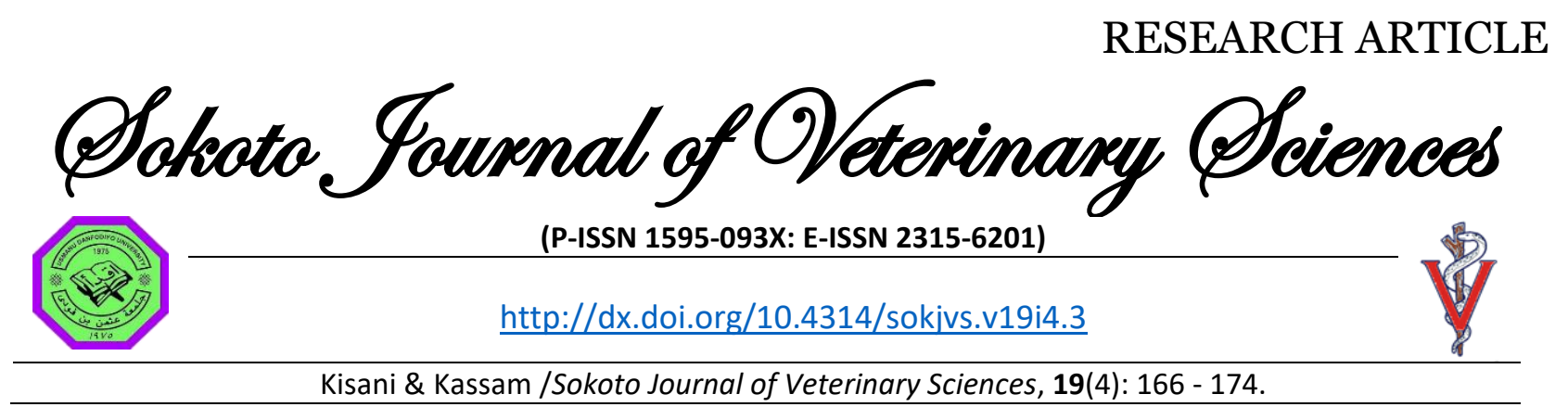

\title{
Surgical measurement of the length of the large intestinal tract in Nigerian local dogs
}

\author{
Al Kisani* \& R Kassam \\ Department of Veterinary Surgery and Diagnostic Imaging, College of Veterinary Medicine, Federal University of \\ Agriculture, Makurdi, Nigeria
}

*Correspondence: Tel.: +234 8033745806; E-mail: abohkisani@yahoo.com

\begin{abstract}
Copyright: (C) 2021
Kisani \& Kassam. This is

an open-access article published under the terms of the Creative Commons Attribution License which permits unrestricted use, distribution, and reproduction in any medium, provided the original author and source are credited.
\end{abstract}

Publication History: Received: 09-04-2021

Revised: 19-06-2021

Accepted: 26-06-2021

\begin{abstract}
This study aimed to determine the total large intestinal length (TLIL) and the lengths of its various segments in Nigerian local dogs. Six (6) adult autochthonous Nigerian local dogs were used for this study. The dogs were premedicated, intramuscularly, with atropine sulphate and xylazine hydrochloride. They were administered anaesthesia and maintained with Thiopentone sodium intravenously. Access to their abdominal cavity was obtained via a mid-ventral abdominal incision. The large intestine was exteriorized and measured from caecum to rectum. The crown-rump length (CRL) and caecum (C) were significantly longer $(p<0.05)$ in the larger dogs $(11-16 \mathrm{~kg})$ compared to the smaller ones (5-10 kg). The colon and rectum (CR), TLIL and the ratio of crown-rump length to intestinal length (CRLT) did not differ significantly $(p>0.05)$ between these two size-wise categories of dogs. The ratios of crown-rump length to weight (CRLW) and large intestinal length to weight (LILW) were significantly higher $(p<0.05)$ in the smaller dogs than in the larger ones. There was a strong correlation between the weight and the CRL (0.53) and between the weight and TLIL (0.66). The average TLIL was $48.3 \mathrm{~cm}$ in the larger dogs and $45.1 \mathrm{~cm}$ in the smaller ones. The average colon and rectum length was $37.7 \mathrm{~cm}$ in the larger dogs and $36.8 \mathrm{~cm}$ in the smaller ones. The average $C$ length was $10.2 \mathrm{~cm}$ in the larger dogs and $8.3 \mathrm{~cm}$ in the smaller ones. The average CRL was 1.5 times the average TLIL in Nigerian local dogs. Conclusion: Body size does not affect the total length of the large intestine of Nigerian local dogs. However, the caecum is significantly longer in the bigger dogs.
\end{abstract}

Keywords: Anaesthesia, Crown-rump length, Dogs, Large intestine, Surgery

\section{Introduction}

The gastrointestinal tract is the immunologic powerhouse of the body and is important to the survival of vital organs such as the brain, heart and lungs (Gelman \& Mushlin, 2004). An active and functionally effective gut is a major determinant of an animal's health (Turan \& Sessler, 2011; Della Rocca \& Coccia, 2013). Gastrointestinal disorders such as ileus, hypoperfusion and ischemia can result in sepsis, multiple organ failure (MOF) and death (Vollmar \& Menger, 2011), with mortality as high as $60-80 \%$. For this reason, the gastrointestinal tract is said to be the motor of MOF (Dobson et al., 2013). Gastrointestinal surgery is the second most commonly performed abdominal surgery in dogs; ovariohysterectomy and ovariectomy are the first (Atilla, 2017). 
Gastrointestinal surgery is also the most commonly performed emergency surgery in dogs (Atilla, 2017). Contemporary veterinary intestinal surgery derives its success from orthodox human surgical orientation (Ellison et al., 2019). Intestinal surgery is carried out in dogs for diagnostic and therapeutic purposes and involves the small intestine much more frequently than the large intestine (Wylie \& Hosgood, 1994; Grimes et al., 2011; Duell et al., 2016). For example, out of 225 intestinal surgeries carried out in a veterinary hospital in dogs only 19 (8.4\%) involved the large intestine whereas 206 (91.6\%) involved the small intestine (Grimes et al., 2011). Enteric biopsy, enterotomy and intestinal resection and anastomosis are some of the surgical procedures commonly performed in the gastrointestinal tract of dogs (Pavletic and Berg, 1996). Peritonitis is an important complication of intestinal surgery due to leakage of intestinal content resulting from dehiscence of the incision site (Pavletic \& Berg, 1996). Intra-abdominal sepsis, hypoalbuminemia and poor surgical technique predispose the patient to intestinal dehiscence (Ellison et al., 2019).

Indications for large intestinal surgery include foreign bodies, neoplasia, intussusceptions (AppleWhite et al., 2001; Morello et al., 2008; Hayes, 2009; Grimes et al., 2011), colonic torsion, colonic strictures, colonic inertia (megacolon), entrapment, and perforations of the colon, rectum and caecum (Bright et al., 1986; Marks, 1986; Clark \& Wise, 1994; Nemeth et al., 2008; Smeak \& Monnet, 2020). Surgical correction of these disorders involves enterocolitis, colo-colic and colorectal anastomoses (Church et al., 1987; Yoon \& Mann, 2008; Sarathchandra et al., 2009; Smeak \& Monnet, 2020).

Managing disorders of the gastrointestinal tract are challenging for clinicians and patients, due to its complex nature which makes it almost inaccessible and due to the limited scope of understanding surrounding the cause and progression of many gastrointestinal conditions (Westermarck, 2016).

The gastrointestinal (GI) tract of animals serves multiple functions including digestion, osmoregulation, and protection (Karasov \& Douglas, 2013). The major functions of the large intestine are extraction of water and electrolytes from the ileal effluent, storage of faeces, and defecation. In addition, microbial fermentation of organic matter that escapes digestion and absorption in the small intestine also occurs in the large intestine (Leib, 2008). This paper reports total large intestinal length in Nigerian local dogs.

\section{Materials and Methods Experimental animals}

Six adults, sexually intact autochthonous Nigerian local dogs of both sexes between the ages of 1 and 3 years and weighing 5-16 kg were used for the study. The dogs were bought from different breeders within Makurdi metropolis, Nigeria and were acclimatized for 4 weeks in kennels at the Veterinary Teaching Hospital of the Federal University of Agriculture, Makurdi, Nigeria. The animals were categorized based on body size into larger (10-16kg) and smaller (5-9kg) size dogs in the course of the experiment.

\section{Presurgical evaluation}

The dogs were fasted for 12 hours and water was withdrawn for 6 hours before surgery. The dogs were taken to a surgery preparation room where vital parameters (temperature, respiratory rate, heart rate and pulse rate) were taken. A thorough physical examination was carried out on each dog to ensure that only healthy dogs were used for this study.

\section{Premedication and anaesthesia}

This study was approved by the ethical committee, Department of Veterinary Surgery and Diagnostic Imaging, College of Veterinary Medicine, Federal University of Agriculture, Makurdi given the permit number PN 2021-003.

The ventral abdomen of each dog was shaved, scrubbed and aseptically prepared for surgery. The dogs were premedicated with atropine sulphate (Jiangsu Huayang Pharmaceutical, China) and Xylazine (VMD, Belgium) at $0.04 \mathrm{mg} / \mathrm{kg}$ and $1 \mathrm{mg} / \mathrm{kg}$ intramuscularly respectively. Normal saline (Dana pharmaceuticals, Nigeria) was administered at 10 $\mathrm{mg} / \mathrm{kg} / \mathrm{hr}$ intravenously using the cephalic vein. Anaesthesia was induced and maintained intravenously with Thiopental sodium (Rotex medica, Germany) at $10 \mathrm{mg} / \mathrm{kg}$. The dogs were draped and the ventral abdomen was disinfected with $0.05 \%$ chlorhexidine (purit ${ }^{\circledR}$ ) (Saro Lifecare Limited, Nigeria) before incisions were made. A mid ventral mid-line incision on the linea alba was made from above the umbilicus to before the pelvic brim using a no. 20 scalpel blade (Figure 1). The incisions were continued on the subcutaneous tissue to expose the linea alba. The linea alba was picked and lifted with thumb forceps. A stab incision was then made on the linea alba using a no. 10 surgical blades with the cutting edge pointing away from the abdominal cavity. The stab incision was then extended cranially and caudally with Metzenbaum scissors. The abdominal cavity was entered into and the various segments of the large 


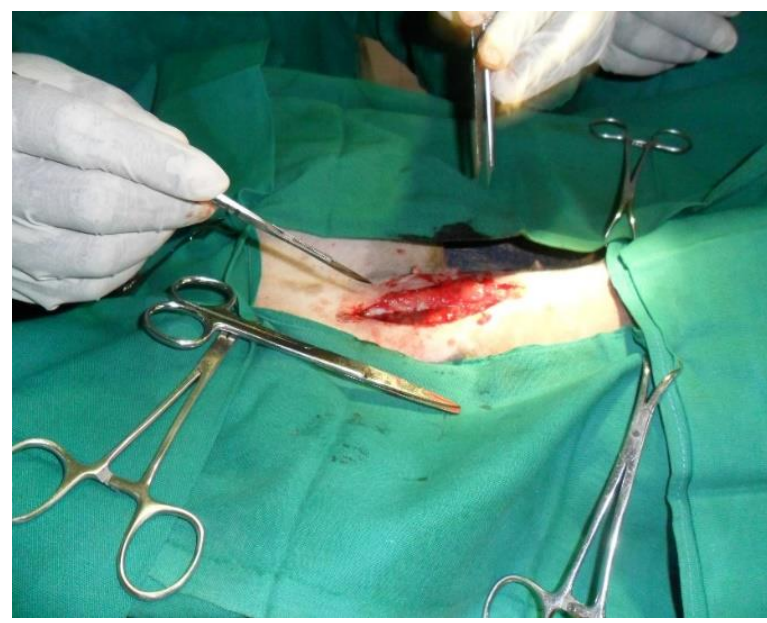

Figure 1: Ventral midline abdominal incision

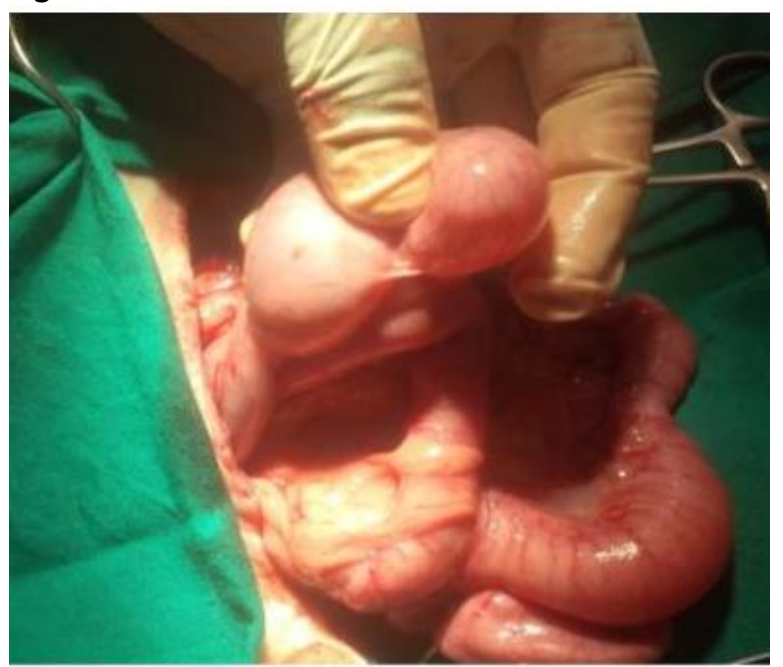

Figure 2: The large intestinal tract was exteriorized before measurement

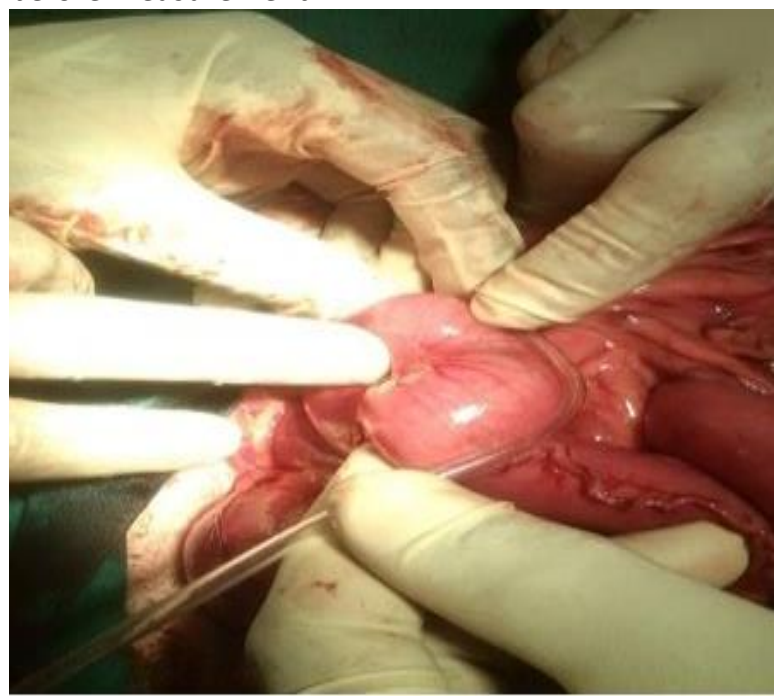

Figure 3: Measurement of large intestinal length using sterile drip set intestine were identified. The thumb and the index fingers were gently inserted into the abdominal cavity and the large intestine was exteriorized and placed on laparotomy pads (figure 2). A sterile drip infusion set was used to measure the length of the individual segment of the large intestine beginning with the caecum, colon and rectum in that order; colon and rectum were measured together (figure 3). After each measurement, the drip set was placed on a calibrated metre rule to determine the length in $\mathrm{cm}$. The large intestine was then gently returned into the abdominal cavity. The abdominal incision was closed in three layers. The peritoneum was closed with chromic catgut (Anhu Kangning Industrial Group, Co. Ltd, China gut) size 3--0 using a simple continuous suture pattern. The subcutaneous tissue was closed with a subcuticular suture pattern using chromic cat (Anhu Kangning Industrial Group, Co. Ltd, China gut) size 3-0 and the skin was closed with nylon (Pal Pharmaceuticals Ltd, China) size 3-0 using a horizontal mattress suture pattern. Ampicillin antibiotic $(22 \mathrm{mg} / \mathrm{kg})$ and pentazocine ( 3 $\mathrm{mg} / \mathrm{kg}$ ) were administered intramuscularly for 3 days respectively.

\section{Statistical analysis}

The results were presented as mean and standard deviation (SD). Student t-test was used to compare the large intestinal length in male and female dogs. Pearson $r$ correlation test was used to compare every pair of data using graph pad prism 5.0. Values of $p<0.05$ were considered statistically significant. The lengths of various parts of the large intestine were calculated using a two-way analysis of variance (ANOVA). A significant difference was detected at a $5 \%$ level of significance (Daniel, 2010).

\section{Results}

The results for crown-rump length, colorectal, caecum, total large intestinal length, the ratio of crown-rump length to intestinal length, ratio of crown-rump length to weight and ratio of large intestinal length to weight are presented in table 1.

The larger dogs $(11-16 \mathrm{~kg})$ had mean weight of $13.3 \pm 1.3 \mathrm{~kg}$ which was significantly higher compared to the smaller dogs $(5-10 \mathrm{~kg})$ with mean weight of $7 \pm 1.5 \mathrm{~kg}$. The mean crown-rump length of the larger dogs was $74.7 \pm 5.0 \mathrm{~cm}$ and was significantly higher than that of the smaller dogs. The length of the caecum in the larger dogs was $10.2 \pm 1.1 \mathrm{~cm}$ which was significantly higher compared to that of the smaller dogs. The ratio of crown-rump length to weight and large intestinal length to weight was significantly lower in the larger dogs compared to that of the smaller dogs. The length of 
colon and rectum and the ratio of crown-rump length over intestinal length did not differ significantly ( $p>0.05$ ) between the two categories of dogs (Table 1 ). There was a weak linear correlation between TLIL and $\mathrm{CRL}$, colorectal and CRL and between colorectal and weight. However, there was a strong non-statistically significant linear correlation between TLIL and weight. There was also a strong and statistically significant linear correlation between caecum and weight (Table 2).

The length of the large intestine was significantly longer in female dogs than in males with a range of $48.5 \mathrm{~cm}$ to $54.4 \mathrm{~cm}$ and an average of $51.13 \pm 1.73 \mathrm{~cm}$ while the male dogs had a range of $38.2 \mathrm{~cm}$ to $46 \mathrm{~cm}$ and an average of $42.33 \pm 2.24 \mathrm{~cm}$ (Table 3 ).

\section{Discussion}

The significantly higher crown-rump length in the bigger dogs with a weight range of $11-16 \mathrm{~kg}$ compared to the smaller dogs with a weight range of 5-10 kg agreed with the report of Hoberman \& Lewis (2017) indicating that crown-rump length is correlated with body weight. The caecum is a large segment of the large intestine with functions that vary according to the species of the animal. Dressman \& Yamada (1991) reported that the dog had a small cecum, similar to that in humans, in line with the dog's carnivorous diet. McGrosky et al. (2016) reported that a high proportion of plant material in the diet of domestic dogs was associated with a longer caecum.
In this present study, the caecum of the bigger dogs (11-16 kg) was significantly larger compared with those of the smaller dogs $(5-10 \mathrm{~kg})$. This might be because bigger dogs tend to eat more of the diet provided by humans and invariably higher proportions of plant material provided in the diet (McGrosky et al., 2016). This might explain the strong and significant correlation between caecum and weight in this study. However, the quantity of plant material in the natural diet of domestic dogs does not influence the total intestinal length, small intestinal length or large intestinal length (McGrosky et al., 2016). The big caecum is important in the storage and breakdown of food and vitamins (Hilderbrand, 1995). The nonsignificant difference in the total large intestinal length between the two different weight categories of dogs in this study agreed with the report of (McGrosky et al., 2016) indicating that the large intestinal length in the carnivorous species did not differ. Differences were, however, observed with the small intestinal tract length. This means that the large intestine volume relative to body weight or size in carnivores is comparatively the same for bigger and smaller ones. This has been attributed to the fact that dogs consume high- protein diet which undergoes simple digestive processes, unlike animals that consume fibre-rich and low protein diets that requires complex digestive processes as a result of which the animals have a large stomach and large intestinal volume greater relative to body size in large species than in smaller ones with the same diet (Chivers \& Hladik, 1980). The genetic

Table 1: Mean total large intestinal length of Nigerian local dogs

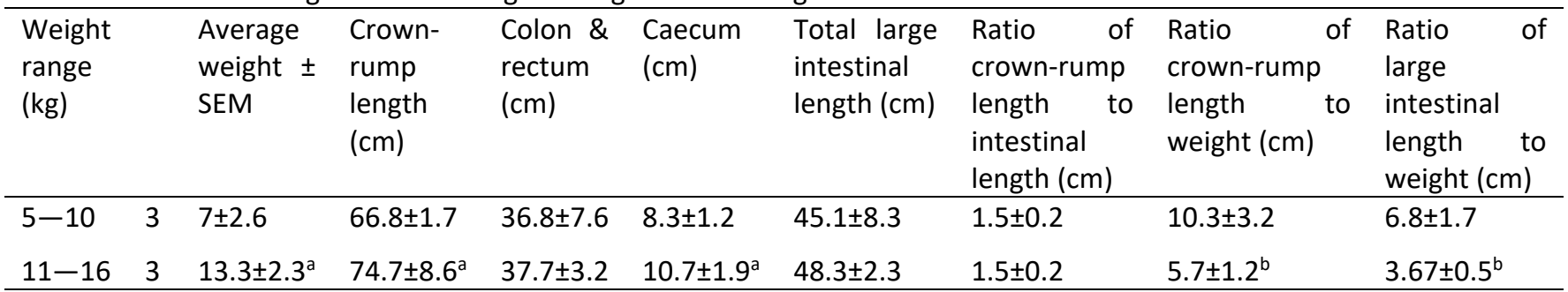

Key: $a=$ significantly higher $(p<0.05) ; b=$ significantly lower $(p<0.05)$

Table 2: Correlations between total length of the large intestine and of its different segments (colorectal and caecum) and crown rump length and weight

\begin{tabular}{lllllll}
\hline & \multicolumn{2}{c}{ Total large intestinal length } & \multicolumn{2}{c}{ Colorectal } & \multicolumn{2}{c}{ Caecum } \\
\hline Crown rump length & $r=0.1931$ & $p=0.7140$ & $r=-0.1013$ & $p=0.8486$ & $r=0.8629$ & $p=0.0269$ \\
Weight & $r=0.6634$ & $p=0.1509$ & $r=0.4743$ & $p=0.3419$ & $r=0.7037$ & $p=0.1187$ \\
\hline
\end{tabular}

Table 3: Length of the large intestine relative to the sex of the dogs

\begin{tabular}{llcccccc}
\hline Sex & \multicolumn{3}{c}{ Length $(\mathrm{cm})$} & Total & Min & Max & Average \\
\hline Male & 46 & 38.2 & 42.8 & 127 & 38.2 & 46 & $42.3 \pm 3.9$ \\
Female & 48.5 & 54.4 & 50.5 & 153.4 & 48.5 & 54.4 & $51.1 \pm 3.0$ \\
\hline
\end{tabular}


determinant for gastrointestinal features correlates with the natural diet of species and is responsible for the variations in the pattern of gastrointestinal development among the different species of animals (Buddington et al., 2000; Widdowson, 1985; Koldovsky et al. 1995).

A couple of researchers correlated the body size of an animal to its gastrointestinal anatomy and function as well as metabolism with smaller species having limited digestive capacities which affect rapid and efficient digestion of food (Demment \& Van Soest, 1985; Kay, 1985; Martin et al., 1985; VanSoest, 1996). The significant increase in the large intestinal length of female dogs compared to the males might be due to higher energy demand during pregnancy or lactation (Bozinovic et al., 1990). The colon and rectum did not also differ significantly between the two weight categories for the same reason enumerated for total large intestinal length. This is expected as colon and rectum together make up the larger proportion of total large intestinal length, 82\% in the smaller dogs $(5-10 \mathrm{~kg})$ and $78 \%$ in the bigger ones $(11-16 \mathrm{~kg})$. Carnivorous species are considered to have a relatively simple gastrointestinal anatomy and a short colon adapted to the digestion of a highprotein diet (Chivers \& Hladik, 1980; Maclamon et al., 1984). The dog colon also differs from that of pigs, monkeys, and humans by the absence of haustra which is a feature that allows for rapid transit of particles than fluids in the dog large intestine (Sutton, 2004; Stevens \& Hume, 1995). The colon of the dog has a shorter mesentery which prevents the colon from moving freely during colonic transit and when the dog is moving. This limit postural differences in motility and transit in the dog as compared with humans.

The ratio of large intestinal length to weight is significantly lower in bigger dogs $(11-16 \mathrm{~kg})$ compared to the smaller ones $(5-10 \mathrm{~kg})$. This agrees with the report of (Barry, 1977) indicating that ratios of intestinal lengths to body lengths and weight are lower for large carnivores than small ones. The ratio of crown-rump length to weight also follows a similar trend. However, the ratio of crown-rump length to large intestinal length did not differ significantly. This might be explained by the hypothesis which states that during the embryological ontogenetic process of body lengthening, there was a corresponding increase or lengthening of primordium of both the mesentery and the intestines as well [Iversen, 1972; McNab, 2008; McGrosky et al., 2016).

Leib \& Matz (1977) reported that the large intestine in a dog is $28-90 \mathrm{~cm}$ in length and the caecum $8-30 \mathrm{~cm}$ in length while (McGrosky et al., 2016) in their work on gross intestinal morphology and allometry in various species of carnivore, reported the minimum large intestinal length to be $14 \mathrm{~cm}$ and the maximum $115 \mathrm{~cm}$. In our study, the minimum large intestinal length was $45.1 \mathrm{~cm}$ and the maximum $48.3 \mathrm{~cm}$. The disparity in TLIL between our study and theirs could be due to differences in breed, method of measurement, flexibility as well as elasticity of the intestinal tract and whether the animals they used were living or a cadaver (Hatton et al., 2015; Muise et al., 2016; Karagule et al., 2016; Bekheit et al., 2020). Previous studies reported measured intestinal length to be longer in cadavers (Exvivo) than in living humans (Invivo) due to the relaxed muscle tone in cadavers (Hosseinpour \& Behdad, 2008; Tacchino, 2015).

Other workers measured intraoperative bowel length using various materials such as suture materials, umbilical tape, ruler and laparoscopic grasper and measuring the intestinal tract either from the mesenteric border, antimesenteric border or midway between (Koivisto et al., 1987; Slater \& Aufses, 1991; Hosseinpour \& Behdad, 2008; Raines et al., 2014; Tacchino, 2015. Muise et al. (2016) reported that rigid measuring tools underestimate intestinal length while flexible materials yield reliable results. Furthermore, that measurement on the mesenteric border produces less variation when compared to measurement on the antimesenteric border. This informed our decision to use a drip infusion set which is a flexible material and the mesenteric border for our measurement in this present study.

(Karagul et al. (2016) reported shortening of the bowel length up to $14 \%$ following repeated measurement. They attributed it to contractions of the bowels after the first measurement which resulted in a shorter measurement in the second. Based on this, all measurements were done once in this study.

The lack of consensus among researchers on the best measurement methods and results is due to the nonavailability of the standardized bowel measurement techniques. In living humans, several different small bowel measurement techniques have been proposed [Shatari et al., 2004; Sinha et al., 2014).

There are many published works involving small bowel length in dogs and humans but there are few or none involving the large intestine (Raines et al., 2014). The large intestine particularly, the colon aside its primary role of aboral transport of undigested nutrients and absorption of water and electrolyte (Holler et al., 1988), takes over the function of the small intestine in patients with short bowel syndrome 
(SBS) and intestinal failure following massive small intestinal resection and anastomosis by slowing down intestinal transit time allowing much fluid to be retained within the gastrointestinal tract which promotes intestinal adaptation (Nordgaard et al., 1994; Kelly et al., 2014; Jeppessen, 2014). The colon also absorbs water, electrolytes and the ability of colonic bacterial to breakdown the poorly absorbed carbohydrate and protein into short-chain fatty acids (SCFAs) further ensures the availability of these elements in SBS patients (Kelly et al., 2014; Jeppesen, 2014; Massironi et al., 2020). This improves the outcome and survival of SBS patients (Todo et al., 1994).

Although there are no reported clinical cases of short bowel syndrome in dogs and cats in Nigeria, Eyarefe et al. (2011), confirmed intestinal surgical conditions such as intussusception, volvulus and torsion which are some of the intestinal conditions that are indications for intestinal resection and anastomosis and consequently short bowel syndrome, constituted $7.5 \%$ of surgical cases managed in some veterinary clinics in southwestern Nigeria.

The result of this study is of importance in patients with short bowel syndrome as it will enable the surgeon to plan adequately for surgical and nutritional intervention that will ensure the survival of the patient and avoid life-threatening complications (Sinha, 2014).

\section{Conflict of Interest}

The authors declare that there is no conflict of interest.

\section{References}

Applewhite AA, Hawthorne JC \& Cornell KK (2001). Complications of enteroplication for the prevention of intussusception re-currence in dogs: 35 cases (1989-1999). Journal of AmericanVeterinary Medical Association, doi: 10.2460/javma.2001.219.1415.

Atilla A (2017). Gastrointestinal surgery -some tips and tricks. Companion Animal, 22(6): 332337.

Barry RE (1977). Length and absorptive surface area apportionment of segments of the hindgut for eight species of small mammals. Journal of Mammal, 58(3): 419-420.

Bekheit M, Ibrahim MY, Tobar W, Galal I \& Elward AS (2020). Correlation between the Total Small Bowel Length and Anthropometric Measures in Living Humans: Cross-Sectional Study. Obesity Surgery, 30(2):681-686.
Bozinovic FFF \& Novoa Veloso C (1990). Seasonal changes in energy expenditure and digestive tract of Abrothrixandinus in the Andes range. Physiological Zoology, 63(12): 12161231.

Bright RM, Burrows CF, Goring R, Fox S \& Tilmant L (1986). Subtotal colectomy for treatment of acquired megacolon in the dog and cat. Journal of American Veterinary Medical Association, 188(12): 1412-1416.

Buddington RK, Malo C \& Elnif J (2000). Ontogenetic development of intestinal nutrient transporters in the mink. American Journal of Physiology, doi.10.1152/ajpregu.2000.279.6.R2287.

Chivers DJ \& Hladik CM (1980). Morphology of the gastrointestinal tract in primatesComparisons with other mammals in relation to diet. Journal of Morphology, 166(3):337-386.

Church EM, Mehlhaff CJ \& Patnaik AK (1987). Colorectal adenocar-cinoma in dogs: 78 cases (1973-1984). Journal of American Veterinary Medical Association, 191:727730.

Clark GN \& Wise LA (1994). Stapled typhlectomy via colotomy for treatment of cecal inversion in a dog. Journal of American Veterinary Medical Association, 204(10): 1641-1643.

Daniel WW (2010). Biostatistics: Basic Concept and Methodology for Health Sciences. John Wiley\& Son, New Delhi., India. P783.

Della Rocca G \& Coccia C (2013). Acute lung injury in thoracic surgery. Current Opinion in Anaesthesiology, doi.10.1097/ACO.0b013e32835c4ea2.

Demment MW \& Van Soest PJ (1985). A nutritional explanation for body-size patterns of ruminant and nonruminant herbivores. American Naturalist, doi.10.1086/284369.

Dobson GP, Faggian G, Onorati F \& Vinten-Johansen J (2013). Hyperkalemic cardio-plegia in adult and pediatric cardiac surgery: end of an era? Frontiers in Physioogy, doi:10.3389/fphys.2013.00228.

Dressman JB \& Yamada K (1996). Animal models for oral drug absorption. In: Pharmaceutical Bioequivalence ( $\mathrm{P}$ Welling, $\mathrm{FL}$ Tse, editors). New York., Marcel Dekker. pp 235-266.

Duell JR, ThiemanMankin KM \& Rochat MC (2016). Frequency of dehiscence in hand-sutured and stapled intestinal anasto-moses in dogs. Veterinary Surgery, doi. 10.1111/vsu.12428. 
Ellison GW, Case JB \& Regier PJ (2019). Intestinal surgery in small animals: historical foundations, current thinking, and future horizons. Veterinary Surgery, 48(7):11711180.

Eyarefe OD, Alonge TO \& Fayemi EO (2011). The Incidence of Intestinal Obstructive Diseases in Selected Veterinary Clinics and Hospitals in South Western Nigeria. Nigerian Veterinary Journal, 32(1): 36 - 39.

Gelman S \& Mushlin PS (2004). Catecholamineinduced changes in the splanchnic circulation affecting systemic hemodynamics. Anesthesiology, doi.10.1097/00000542-200402000-00036.

Grimes JA, Schmiedt CW, Cornell KK \& Radlinksy MA (2011). Identification of risk factors for septic peritonitis and failure to survive fol-lowing gastrointestinal surgery in dogs. Journal of American Veterinary Medical Association, 238(4): 486-494.

Hatton GB, Yadav V, Basit AW \& Merchant HA (2015). Animal Farm: Considerations in Animal Gastrointestinal Physiology and Relevance to Drug Delivery in Humans. Journal of Pharmaceutical Sciences, doi 10.1002/jps.24365.

Hayes G (2009). Gastrointestinal foreign bodies in dogs and cats: a retrospective study of 208 cases. Journal of Small Animal Practice, 50(11): 576-583.

Hildebrand M (1995). Análisedaestruturadosvertebrados. São Paulo, Atheneu. Pp 700.

Hoberman AM \& Lewis EM (2017). Juvenile Toxicology Testing. In: Reproductive and Developmental Toxicology (RC Gupta, editor). Academic press. Pp 129-144.

Holler H, Figge A, Richter J \& Breves G (1988). Calcium and in-organic phosphate net absorption from the sheep colon and rectum perfused in vivo. Journal of Animal Physiology and Animal Nutrition, 59:9-15.

Hosseinpour M \& Behdad A (2008). Evaluation of small bowel measurement in alive patients. Surgical and Radiologic Anatomy, doi.10.1007/s00276-008-0398-2.

Iversen JA (1972). Basal energy metabolism of mustelids. Journal of Comparative Physiology, 81:341-344.

Jeppesen PB (2014). Spectrum of short bowel syndrome in adults: intestinal insufficiency to intestinal failure. Journal of Parenteral and Enteral Nutrition, doi.10.1177/0148607114520994.

Karagul S, Kayaalp C, Kirmizi S, Tardu A, Ertugrul I, Tolan K \& Sumer F (2016). Influence of repeated measurements on small bowel length. Springer Plus, 5(1): 1828.

Karasov WH \& Douglas AE (2013). Comparative digestive physiology. Comprehensive Physiology, 3(2):741-83.

Kay RNB (1985). Comparative studies of food propulsion in ruminants. In: Physiological and pharmacological aspects of the reticulorumen (LAA Ooms, AD Degryse, ASJAM Van Miert, editors) Dordrecht., The Netherlands. Pp 155-170.

Kelly DG, Tappenden KA, Winkler MF (2014). Short bowel syndrome: highlights of patient management, quality of life, and survival. Journal of Parenteral and Enteral Nutrition, doi.10.1177/0148607113512678.

Koivisto $P$, Lempinen $M$ \& Miettinen TA (1987). Fecal bile acids related to small-bowel length before and after ileal exclusion. Scandinavian Journal of Gastroenterology, doi.10.3109/00365528709011144.

Koldovský $O$, Dobiášová $M$, Hahn $P$ \& Kolinska J (1995). Development of gastrointestinal functions. Physiological Research, 44: 341348.

Leib M \& Matz M (1997). Diseases of the intestines. In: Practical Small Animal Internal Medicine (M Leib, W Monroe, editors). Philadelphia, WB Saunders. Pp 685-760.

Leib MS (2008). Large intestine. In: Small Animal Gastroenterology (MJ Steiner, editor). SchlüterscheVerlagsgesellschaftmbH \& Co.KG, Hans-Böckler-Allee 7, 30173 Hannover. Pp 217-240.

Maclarnon A, Martin RD, Chivers DJ \& Hladik CM (1984). Some aspects of gastrointestinal allometry in primates and other mammals. International Journal of Primatology, 5(4):358-358.

Marks A (1986). Torsion of the colon in a rough Collie. Veterinary Record, 118(14): 400.

Martin RD, Chivers DJ, MacLarnon AM \& Hladik CM (1985). Gastrointestinal allometry in Primates and other mammals. In: Size and Scaling in Primate Biology: Advances in Primatology (WL Jungers, editor). Springer., Boston. Pp 61-89.

Massironi, S, Cavalcoli F, Rausa E, Invernizzi P, Braga $M$ \& Vecchi M (2020). Understanding short 
bowel syndrome: Current status and future perspectives. Digestive and Liver Disease, doi.10.1016/j.dld.2019.11.013.

McGrosky A, Navarrete A, Isler K, Langer P \& Clauss M (2016). Gross intestinal morphometry and allometry in Carnivora. Eurpean Journal of Wild life Research, doi 10.1007/s10344-0161011-3.

McNab BK (2008). An analysis of the factors that influence the level and scaling of mammalian BMR. Comparative Biochemistry and Physiology part A: Molecular \& Integrative Physiology, 151(1):5-28.

Morello $E$, Martano $M$, Squassino $C$, lussich $S$, Caccamo R, Sammartano F, Bellino C \& Buracco P (2008). Transanal pull-through rectal amputation for treatment of colorectal carci-noma in 11 dogs. Veterinary Surgery, 37(5): 420-426.

Muise DE, Tacket JJ, Callender AK, Gandotra N, Bamdad MC \& Cowles RA (2016). Accurate assessment of bowel length: the method of measurement matters. Journal of Surgical Research, 206(1):146-150.

Nemeth T, Solymosi N \& Balka G (2008). Long-term esults of subto-tal colectomy for acquired hypertrophic megacolon in eight dogs. Journal of Small Animal Practice, doi.10.1111/j.1748-5827.2008.00624.x.

Nordgaard I, Hansen BS \& Mortensen PB (1994). Colon as a digestive organ in patients with short bowel. Lancet, doi.10.1016/s01406736(94)91220-3.

Pavletic MM \& Berg J (1996). Gastrointestinal surgery. In: Complications in Small Animal Surgery (AJ Lipowitz, DD Caywood, CD Newton, A Schwartz, editors). Williams \& Wilkins, Baltimore. Pp 365-398.

Raines D, Arbour A, Thompson HW, Figueroa-Bodine J \& Joseph S (2014). Variation in small bowel length: factor in achieving total enteroscopy? Digestive Endoscopy, doi.10.1111/den.12309.

Sarathchandra SK, Lunn JA \& Hunt GB (2009). Ligation of the caudal mesenteric artery during resection and anastomosis of the colorectal junction for annular adenocarcinoma in two dogs. Australian Veterinary Journal, doi.10.1111/j.1751-0813.2009.00473.x.

Shatari T, Clark MA, Lee JR \& Keighley MRB (2004). Reliability of radiographic measurement of small intestinal length. Colorectal Disease, 6(5):327-329.
Sinha R, Trivedi D, Fallis S \& Murphy PD (2014). Small intestinal length measurement on $M R$ enterography: comparison with in vivo surgical measurement. American Journal of Roentgenol, doi.10.2214/AJR.13.11944.

Slater G \& Aufses Jr AH (1991). Small bowel length in Crohn's disease. American Journal of Gastroenterology, doi.10.1007/s00384-0020475-7.

Smeak DD \& Monnet E (2020). Colectomy and subtotal colectomy. In: Gastrointestinal Surgical Techniques in Small Animals (E Monnet, DD Smeak, editors). Wiley Blackwell. Pp 209- 217.

Stevens CE \& Hume ID (1995). Comparative physiology of the vertebrate digestive system, Second edition, Cambridge University Press. Cambridge, pp 46-93.

Sutton SC (2004). Companion animal physiology and dosage form performance. Advanced Drug Delivery Reviews, 56(10):1383-1398.

Tacchino RM (2015). Bowel length: measurement, predictors, and impact on bariatric and metabolic surgery. Surgery for Obesity and Related Diseases, 11(2): 328-34.

Todo S, Reyes J, Furukawa H, Elmagd KA, Lee RG, Tzakis A, Rao AS \& Starzl TE (1995). Outcome analysis of 71 clini-cal intestinal transplantations. Annals of Surgery, doi.10.1097/00000658-199509000-00006.

Turan A \& Sessler DI (2011). Steroids to ameliorate postoperative pain. Anesthesiology, 115: 4579. doi:10.1097/ALN.0b013e31822a2871.

VanSoest PJ (1996). Allometry and ecology of feeding behavior and digestive capacity in herbivores: A review. Zoo Biology, 15(5): 455-479.

Vollmar B \& Menger MD (2011). Intestinal ischemia/reperfusion: microcirculatory pathology and functional consequences. Langenbeck's Archives of Surgery, 396:1329. doi:10.1007/s00423-010-0727-x.

Westermarck E (2016). Chronic diarrhea in dogs: what do we actually know about it? Topics in Companion Animal Medicine, doi.10.1053/j.tcam.2016.03.001.

Widdowson EM (1985). Development of the digestive system: comparative animal studies. American Journal of Clinical Nutrition, doi.10.1093/ajcn/41.2.384.

Wylie KB \& Hosgood GH (1994). Mortality and morbidity of small and large intestinal surgery in dogs and cats: 74 cases (1980- 
1992). Journal of American Animal Hospital Association, 30: 469-474.

Yoon HY \& Mann FA (2008). Bilateral pubic and ischial osteotomy for surgical management of caudal colonic and rectal masses in six dogs and a cat. Journal of American Veterinary Medical Association 